\title{
Identificação de depósitos tecnogênicos em um reservatório de abastecimento de água da cidade de Pelotas (RS)
}

\section{Identification of the technogenic deposits in water supply reservoir in the city of Pelotas (RS)}

\author{
Carina Cristiane Korb $^{\text {ab }}$, Dirce Maria Antunes Suertegaray ${ }^{\text {ac }}$ \\ ${ }^{\mathrm{a}}$ Universidade Federal do Rio Grande do Sul \\ bcarinac.korb@gmail.com, cdircesuerte@gmail.com
}

\begin{abstract}
RESUMO
Este trabalho analisa a formação e constituição dos depósitos derivados do assoreamento no Reservatório Santa Bárbara (Pelotas - RS). Desta forma, foi feito o mapeamento do uso e ocupação do solo da bacia hidrográfica deste corpo d’água, referente a duas épocas: 1988 e 2002. Posteriormente, os depósitos foram caracterizados e classificados, de acordo com sua estrutura, gênese e composição. Para isto, foi feito testemunhagem na confluência de cada um dos cinco afluentes. Os resultados obtidos foram a quantificação das classes de uso e ocupação do solo, a identificação e classificação dos depósitos tecnogênicos e a verificação, nestes, de fases de menor e maior antropização.
\end{abstract}

Palavras-chave: Depósitos tecnogênicos; Reservatório; Tecnógeno.

\begin{abstract}
This study analyzes the formation and constitution of deposits derived from silting at the Reservoir Santa Barbara (Pelotas - RS). Thus, there was the mapping of the land use of the watershed of this water body, and it is related to two periods of time: 1988 and 2002. Later, the deposits were characterized and classified according to their structure, genesis and composition. In order to do this, there was a geologic core sample at the confluence of each one of the five affluent rivers. The results were quantification of classes of use and soil occupation, the identification and classification of these tehnogenic deposits and the checking of lower and higher stages of anthropization.
\end{abstract}

Keywords: Technogenic deposits; Reservoir; Technogene.

\section{Introdução}

As reflexões sobre a efetividade da relação entre o homem e a natureza nos estudos do Quaternário surgem em temáticas como, por exemplo, do Tecnógeno e dos depósitos tecnogênicos. Trata-se de uma abordagem estabelecida, principalmente, a partir da publicação internacional dos artigos de Chemekov (1983) e Ter-Stepanian (1988), tendo sido desenvolvida no Brasil a partir da década de 1990, assumindo importância maior com a realização do $1^{\circ}$ Encontro Brasileiro do Tecnógeno, em 2005.

Esta temática traz à Geologia, Geomorfologia e, também à Geografia, abordagens diferenciadas no sentido de promover concepções teóricas para o entendimento dos ambientes transformados pelas práticas humanas modificadoras das paisagens atuais.

Segundo Korb (2006), os depósitos tecnogênicos constituem-se como testemunhos materiais de ambientes antropizados e podem resultar de processos naturais modificados pela apropriação do espaço pela sociedade como, por exemplo, o assoreamento de corpos d'água produzido pelo uso e ocupação do solo. Nestas acumulações sedimentares é possível encontrar artefatos manufaturados pelo homem moderno, como, por exemplo, fragmentos de plástico, vidro, pregos, entre outros.

Segundo Oliveira (1990), classificam-se geneticamente em construídos - aterros, corpos de rejeitos; induzidos - erosão, assoreamento, aluviões modernos; e modificados - depósitos naturais alterados tecnogenicamente por efluentes, adubos. Nolasco (1998) inclui as classes retrabalhados e remobilizados.

Na constituição desses depósitos, para Fanning \& Fanning (1989), enquadram-se materiais úrbicos (fragmento de tijolo, vidro, concreto, asfalto, pregos, plástico, metais diversos, pedra britada, cinzas, detritos de demolição de edifícios), materiais gárbicos (material detrítico com lixo orgânico de origem humana e que, apesar de conterem artefatos em quantidades menores que a dos materiais úrbicos, são suficientemente ricos em matéria orgânica para gerar metano em condições anaeróbicas), espólicos (materiais terrosos escavados e redepositados por operações de terraplanagem e depósitos de assoreamento induzidos pela erosão acelerada; são materiais que contém muito pouca quantidade de artefatos) e dragados (materiais terrosos provenientes 
da dragagem de cursos d'água e comumente depositados em diques, em cotas topográficas superiores às da planície aluvial).

Mais recentemente, Peloggia (1999), a partir destas propostas, propôs uma classificação integrada que consiste numa aplicação de forma sequencial dos parâmetros gênese, composição, estrutura, forma de ocorrência e ambiente tecnogênico.

Estas acumulações sedimentares denominadas de tecnogênicas, segundo Ter-Stepanian (1988), "caracterizam uma 'classe genética independente', embora possam ser traçadas analogias com depósitos naturais". A originalidade apresentada por estes depósitos, cuja gênese e constituição são representativas da intervenção antropogênica, configurando-se como elementos diferenciais na compreensão do tempo geológico, caracteriza para alguns autores o advento de um novo período na escala do tempo geológico, o Tecnógeno ou Quinário.

Este novo conceito objetiva contribuir com a atual subdivisão temporal do Quaternário, no sentido de valorizar o advento da ação humana nas transformações ambientais. Neste sentido, Peloggia (1999) sugere o Tecnógeno como uma época do Quaternário que se constituiria no Pleistoceno (Quaternário antigo), Holoceno (período de transição) e finalmente no Tecnógeno, que se efetiva na atualidade, sendo marcado pelo advento de processos geológicogeomorfológicos, por vezes acelerados, diferenciados em relação aos antecedentes.

De modo a resgatar a temática exposta, objetivou-se analisar a influência da ação humana na formação e constituição de depósitos derivados do assoreamento no Reservatório Santa Bárbara, na cidade de Pelotas, Estado do Rio Grande do Sul. Para tanto, foram definidos os seguintes objetivos específicos:

1. Realizar testemunhos geológicos na desembocadura dos afluentes do reservatório para uma análise vertical da coluna estratigráfica dos depósitos;

2. Caracterizar os depósitos identificados, segundo sua composição e classificação;

3. Delimitar e mapear a cobertura vegetal e ocupação do solo presentes na bacia de captação do manancial. A intenção com esse mapeamento é a caracterização das transformações espaço-temporais que ocorreram na bacia no que tange ao uso e ocupação do solo, tentando indicar possíveis causas no processo de constituição dos depósitos.

\section{Descrição da Área de Estudos}

O Reservatório Santa Bárbara situa-se na área urbana do município de Pelotas, estado do Rio Grande do Sul (figura 1). Em seus aspectos geológicogeomorfológicos regionais, sua bacia de captação localiza-se na faixa de contato entre dois compartimentos estruturais e geomorfológicos, o
Embasamento Pré-Cambriano, constituído de rochas granito-metamórficas, caracterizado por um relevo de coxilhas de topo convexo, e a Planície Costeira, cuja litologia é formada pelos sistemas deposicionais do tipo laguna-barreira constituído, morfologicamente, de terraços quaternários.

A bacia de captação apresenta uma área de, aproximadamente, 18 mil hectares (ha) e abrange parte da área urbana e rural do município, tendo suas principais nascentes situadas no distrito de Monte Bonito. No entorno do reservatório encontram-se os bairros Santa Terezinha, Sítio Floresta, Cohab Lindóia e o Distrito Industrial Anacleto Firpo.

O reservatório foi construído no ano de 1968 a partir de uma barragem de terra compactada que represa e armazena águas provenientes da bacia hidrográfica para o abastecimento público dos bairros Centro, Zona do Porto, Bairro Navegantes, Vila Fátima, Bairro Fragata, Distrito Industrial e Vila Cohab. Possui três setores principais de contribuição, embora existam outros de pequena extensão: Setor do arroio Santa Bárbara, Setor do arroio do Meio e o Setor da Sanga da Barbuda.

O Setor do arroio Santa Bárbara apresenta quatro contribuintes, destacando-se o de maior extensão, cujas nascentes se encontram nos terrenos cristalinos. O curso principal drena locais com lavouras de arroz irrigado, onde as águas são represadas, bem como áreas urbanas do entorno da BR 392. O Setor do arroio do Meio possui três afluentes principais, desenvolve-se em compartimentos cristalino e sedimentar, e também drena terrenos com lavouras de arroz irrigado, florestamento, bairro residencial e industrial. Já o Setor da Sanga da Barbuda, inteiramente situado sobre compartimento sedimentar, drena as áreas mais modificadas da bacia, uma vez que recebe contribuições de canais de drenagens urbanas, incluindo rodoviárias e industriais, bem como agrícolas.

Dessa forma, o entorno do reservatório se caracteriza como um local de expansão urbano-industrial (bairros urbanos, ocupações irregulares, distrito industrial) e de atividades agropecuárias, como florestamento de eucalipto, orizicultura e, em menor escala, fruticultura. Conforme o II Plano Diretor do município (Pelotas, 1980), insere-se em uma Zona de Preservação Municipal.

\section{Metodologia}

\subsection{Mapeamento do Uso e Ocupação do Solo}

Os procedimentos metodológicos adotados para o cumprimento dos objetivos propostos consistiram, inicialmente, no mapeamento do uso e ocupação do solo da bacia hidrográfica do arroio Santa Bárbara, alimentadora do manancial. Para tanto, foram definidos dois períodos temporais de análise: 1988 e 2002. 


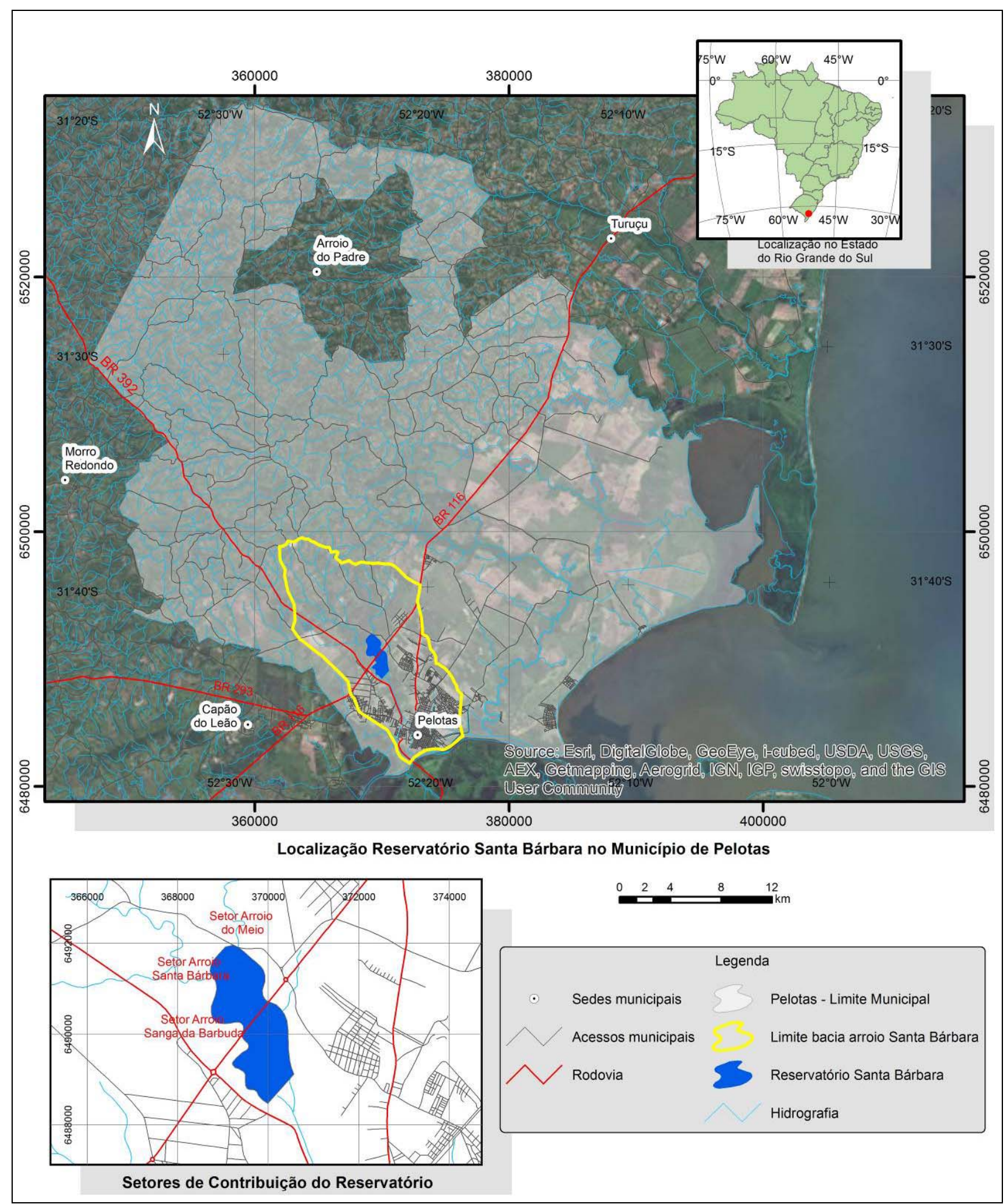

Figura 1: Localização do Reservatório Santa Bárbara - Pelotas/RS

$\mathrm{Na}$ interpretação das informações espaciais, de forma a cartografá-las, foram utilizadas ferramentas de geoprocessamento, como a Classificação Supervisionada (Método MAXVER), que permitiu gerar mapas com as classes desejadas, possuindo como base as imagens orbitais dos satélites LANDSAT TM5 (03/04/1988) e LANDSAT 7 (17/11/2002). Para isso foi concebida uma composição colorida falsa-cor com as bandas 3B4R5G.

Para uma classificação adequada às pretensões do trabalho, foram definidas as seguintes classes: (1) Corpos d'água, incluindo os rios ou arroios, lagos, açudes e o Reservatório; (2) Mata, incluindo mata ciliar, florestamentos e mata nativa; (3) Campo, incluindo as formações de campos limpos e pastagens; 
(4) Agricultura, incluindo áreas com solo exposto revolvido para fins agrícolas e lavouras de arroz; (5) Área urbanizada, incluindo aglomerados urbanos.

Todas as operações subsequentes a esta etapa foram realizadas no ambiente computacional do programa Spring 4.1.1, e a edição gráfica final dos mapas, no ArcGis 10.1 .

\subsection{Identificação e Análise dos Depósitos}

Na etapa de identificação dos depósitos optou-se pela coleta de cinco amostras pontuais, em locais cobertos pela lâmina d'água, na desembocadura dos afluentes, representativas das áreas recentemente assoreadas (figura 2). A técnica adotada foi a testemunhagem com testemunhador a percussão e tubos de PVC, de $50 \mathrm{~mm}$ de diâmetro e 1,5 m de comprimento.

Em laboratório, os tubos foram abertos, separados em duas parcelas para retirada de amostras. De forma a atingir os objetivos propostos, estas amostras de sedimento foram submetidas à identificação da coloração dos grãos, da textura, de artefatos tecnogênicos, do teor de matéria orgânica e de metais pesados.

A variação da coloração dos grãos do perfil foi identificada tomando-se como referência Rock Color Chart, onde os códigos identificam a alteração dos materiais, obtendo-se um total de 18 amostras dos 5 testemunhos coletados.

Uma vez selecionadas e identificadas as amostras, procedeu-se à sua secagem em estufa, a aproximadamente $60^{\circ} \mathrm{C}$. Seco, este material sofreu uma desagregação preliminar com o auxílio de almofariz e pistilo com proteção de borracha, para evitar a ruptura dos grãos. Após serem desagregadas, as amostras foram quarteadas, reduzidas em uma alíquota representativa da amostra total e pesadas em frações de aproximadamente 30 gramas.

Para compor o reconhecimento da constituição antropogênica, enfatizou-se a análise da composição textural, efetuada mediante procedimento mecânico: método do peneiramento para partículas maiores que 0,062 mm (<4Ø) de diâmetro, e método de pipetagem, com base na Lei de Stokes, para partículas menores que $0,062 \mathrm{~mm}(>4 \varnothing)$, conforme classificação granulométrica de Wentworth (1922).

Nesse estudo realizou-se uma única pipetagem tendo em vista a necessidade de obtenção da concentração total dos grãos de tamanho silte e argila. Os dados obtidos foram plotados no programa de análise estatística Panicom/SAG, obtendo-se os parâmetros texturais com base no diagrama de Shepard (1954).

$\mathrm{Na}$ tentativa de caracterizar de forma mais completa as amostras e reconhecer materiais úrbicos, cada alíquota contida nas peneiras foi também colocada em uma placa de Petri e, com lupa binocular, procurou-se reconhecer a existência de detritos sob a forma de artefatos antropogênicos, como fragmentos de tijolos, vidro, concreto, plástico, pregos, asfalto.
De posse dos resultados referentes à textura, procedeu-se ao reconhecimento dos materiais gárbicos através da identificação da concentração da matéria orgânica. Para isso, foram selecionadas as amostras que apresentaram textura de 'lama', 'lama com areia' e ‘areia com lama', adotando-se o método proposto por Wetzel (1975) o qual consiste em eliminar a matéria orgânica (M.O.) das frações de silte e argila de cada amostra por meio da calcinação em mufla, de alíquotas de aproximadamente 2 gramas de sedimento, por tempo determinado (4 horas). O teor de matéria orgânica é a relação entre a perda de massa, decorrente desta queima e o peso inicial da amostra.

Para complementar as características dos depósitos e reconhecer sua antropização fez-se, também, análise química nos sedimentos que consistiu na identificação da concentração de metais pesados. Foram selecionadas todas as amostras dos testemunhos T1 e T4 e, amostras de topo dos testemunhos T2, T3, T5.

Os metais reconhecidos foram cobre $(\mathrm{Cu})$, cromo $(\mathrm{Cr})$, chumbo $(\mathrm{Pb})$ e zinco $(\mathrm{Zn})$, pois segundo Förstner \& Müller (1974) apud Esteves (1988), estão entre os elementos-traço mais tóxicos à maioria dos organismos, incluindo o do homem, juntamente com o mercúrio, cádmio e níquel.

O procedimento de preparo das amostras de sedimento para análise química foi a peneiração a úmido, com peneiras de PVC e malhas de nylon 0,062mm, para obtenção da fração silte/argila $(<0,062 \mathrm{~mm})$, pois os elementos-traço estão associados principalmente às partículas de silte e argila; esta fração é a mais semelhante à granulometria do material carreado em suspensão, correspondente à mais importante forma de transporte para os sedimentos em ambiente aquático; e a peneiragem não altera as concentrações dos metais por remobilização (Förstner 1989 apud Rodrigues 1997).

As amostras, uma vez peneiradas, foram acondicionadas em sacos plásticos, vedados, e mantidas resfriadas a $4^{\circ} \mathrm{C}$ para a digestão de metais totais. Para a determinação de metais totais realizou-se a solubilização das amostras com emprego de ácido nítrico e fluorídrico, em sistema fechado, sob aquecimento em estufa, completando a dissolução em frasco aberto. A determinação dos metais foi obtida através de um espectômetro de absorção atômica (EEA/Chama Ar-Acetileno).

Valendo-se dos dados obtidos a partir da identificação da concentração total dos metais nas amostras, foi identificado o grau de poluição antropogênica dos sedimentos através de indicadores de contaminação/poluição: o Fator de Contaminação (FC) de Hakanson (1980) e o Índice de Geoacumulação (Igeo) de Müller (1979). O FC define o enriquecimento de um metal no sedimento em relação à sua concentração natural (background), sendo obtido a partir da razão entre a concentração do elemento no sedimento e o background. 


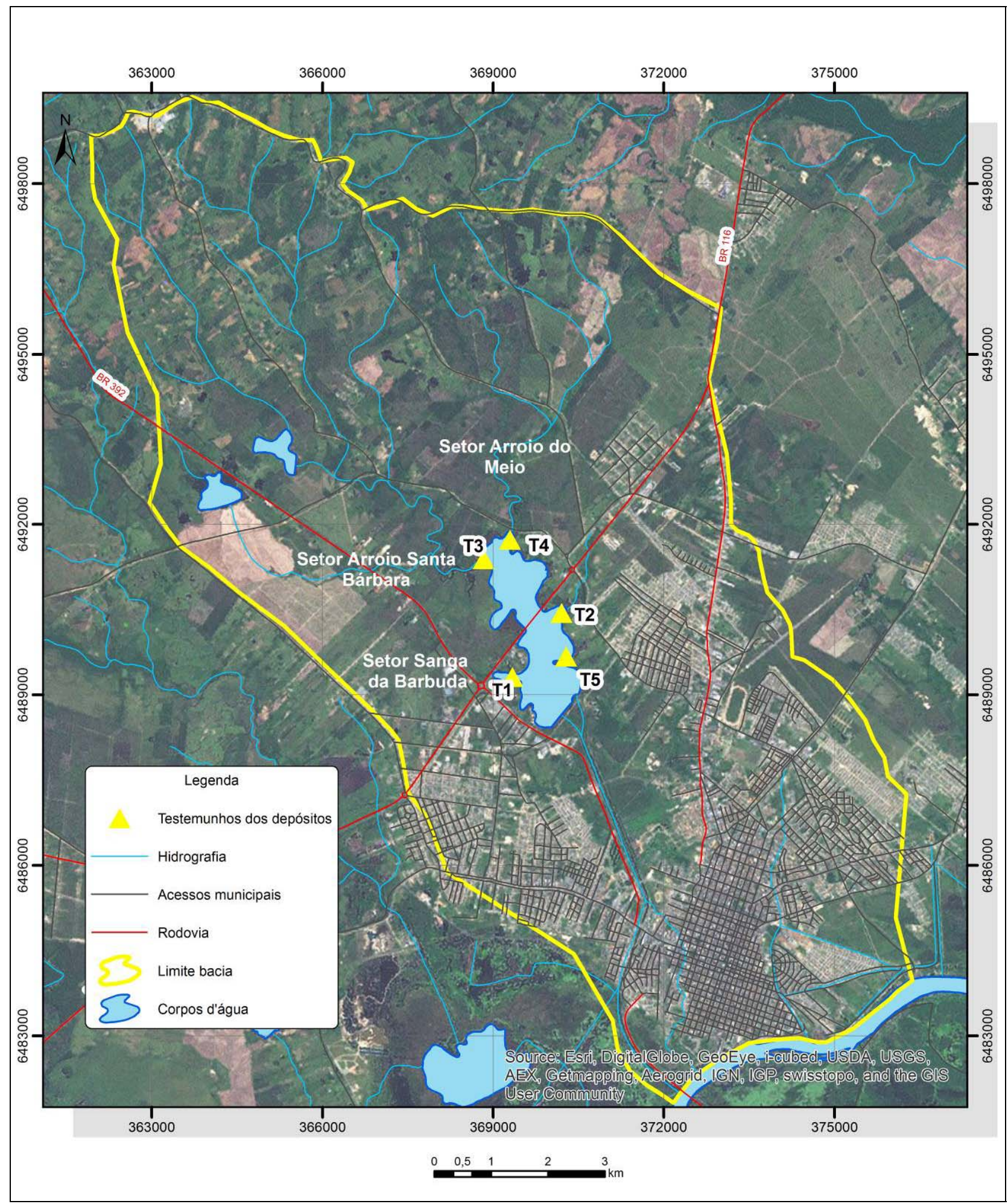

Figura 2: Localização dos testemunhos geológicos

O Igeo permite reconhecer graus de poluição e estabelece a relação entre os teores de metais encontrados nos sedimentos analisados e um valor referencial equivalente à média mundial para metais associados às argilas.

O valor obtido permite classificar os níveis de enriquecimento dos metais em sete extratos, com intensidades progressivas de contaminação.
Os valores de background considerados foram a média mundial dos sedimentos proposta por Turekian \& Wedepohl (1961), a concentração do Folhelho Padrão, que também é uma média mundial definida pela United States Environmental Protection Agency (U.S.EPA), e os valores médios de dados geoquímicos das rochas do Embasamento Pré-Cambriano, propostos por Oliveira (2001). Todos estes dados já foram 
utilizados nos estudos de Franzen (2001) e Soares (2002).

A utilização da média mundial e do Folhelho como padrão de referência justifica-se pelo fato destas rochas apresentarem composição química e mineralógica aproximadamente semelhante à fração granulométrica analisada nos sedimentos dos depósitos do Reservatório Santa Bárbara (menor que 0,062 mm). Quanto à utilização dos valores de Oliveira (2001), a justificativa provém do fato de estes dados se associarem à estrutura geológica regional, o Embasamento Pré-Cambriano.

\section{Resultados e discussões}

\subsection{Uso e ocupação do solo: a dinâmica espacial na bacia hidrográfica do arroio Santa Bárbara}

O procedimento técnico de construção dos mapas de uso e ocupação do solo por meio da classificação digital e as associações analíticas possibilitaram revelar transformações, em um período de 14 anos, nas classes mapeadas (tabela 1 e figuras 3 e 4 ).

Tabela 1: Relação das áreas (ha) obtidas das Classes de Uso e Ocupação do Solo

\begin{tabular}{ccc}
\hline Classes & Ano de 1988 & Ano de 2002 \\
\hline Corpos d'água & 310.6 & 431,6 \\
Mata & $3.020,9$ & $3.321,8$ \\
Campo & $6.882,7$ & $4.991,4$ \\
Agricultura & 105.9 & 573,5 \\
Área Urbanizada & $3.136,4$ & $4.125,4$ \\
\hline
\end{tabular}

As áreas com solo exposto, revolvido para fins agrícolas, como lavouras de arroz e hortigranjeiros inseridos na Classe Agricultura somavam em 1988 uma área de 105,9 hectares e, em 2002, 573,5 ha. Juntamente com as demais classes, avançou sobre áreas de campo, onde em 1988 era de 6.882,7 hectares e em 2002, de 4.991,4 hectares.

Dois locais na bacia hidrográfica em sua porção mediana, um a NW e outro a NE, correspondem ao cultivo de arroz desenvolvido em pequenos e médios estabelecimentos rurais. É preciso explicitar que a variação de suas áreas espaciais, conforme podem ser visualizadas nos mapas de 1988 e 2002, possivelmente encontra-se associada às datas das imagens orbitais utilizadas na classificação digital.

O mapa de 1988 elaborado com imagem do mês de abril (período da colheita) apresenta a cultura do arroz com uma porção menor, quando comparada ao mapa de 2002, cuja imagem corresponde ao mês de novembro (período de preparo do solo com maior exposição), justificando o comportamento espectral e áreas obtidas. Outros pontuais aumentos de áreas desta classe mapeada associam-se à expansão de culturas respectivas a hortifrutigranjeiros que se desenvolveram com o crescimento do número de indústrias alimentícias, quando da implantação do sítio industrial no município, no transcorrer das décadas de 1980 e 1990.
A expansão urbana experimentada pelo município de Pelotas acabou por se refletir na bacia hidrográfica formadora do Reservatório Santa Bárbara, modificando características originais, o que possivelmente pode estar contribuindo, desde então, para a degradação da qualidade das águas dos arroios contribuintes e, consequentemente, do manancial em questão. Em razão da precariedade do planejamento, com relação à ocupação do solo, pela pontual inexistência de um sistema de esgotamento sanitário e falta de programas de educação sanitária e ambiental que abranjam toda a população, além da multiplicidade de atividades na região, em um misto de urbana e rural, o tempo de vida útil e a qualidade das águas do Reservatório Santa Bárbara vem apresentando um crescente comprometimento.

O processo de urbanização de Pelotas teve um papel muito importante na dinâmica ambiental processada na área em estudo. Este crescimento das áreas urbanas de 3.136,4 hectares em 1988 para 4.125,4 hectares em 2002, que pode ser perfeitamente visualizado ao se compararem os mapas das duas épocas em questão, veio acompanhado de pontuais ocupações irregulares, retirada/substituição da cobertura vegetal, desencadeando o assoreamento do Reservatório Santa Bárbara e de cursos fluviais que nela desembocam.

No entanto, o mapeamento da área suscitou questões bastante interessantes que em princípio parecem contraditórias, como o aumento da área de mata que se expandiu sobre áreas de campo, simultaneamente ao aumento das áreas urbanas e agrícolas, como fica claro na comparação dos mapas de uso do solo e ocupação da bacia hidrográfica do arroio Santa Bárbara de 1988 e 2002.

A necessidade de expansão das áreas urbanas, em virtude do inchaço da cidade, levou a população mais pobre a deslocar-se para as zonas periféricas, onde as terras custavam menos e com a possibilidade de ocupar áreas desabitadas no espaço físico da bacia. Mas esta ocupação incorreu em pontuais ações irregulares, posto que se deu sob locais próximos às áreas de mata ciliar, que pelo artigo $2^{\circ}$ do Código Florestal Brasileiro devem ser preservadas, assim como as áreas do entorno dos corpos d’água, neste caso, o Reservatório.

O aumento da área de mata na bacia de captação do Reservatório Santa Bárbara, de 3.020,9 hectares em 1988 para 3.321,8 hectares em 2002 deveria então, de acordo com a interpretação mais usual, aumentar a proteção do solo, diminuindo os impactos das chuvas e reduzindo sua erosividade, resultando num decréscimo de processos erosivos pelo escoamento superficial, o que evitaria o assoreamento no reservatório. Não obstante, é importante salientar que, com base na análise das imagens utilizadas, este aumento da área de mata se deu com a expansão do plantio de espécies exóticas (diferença clara quando se analisam as texturas das matas), como o eucalipto e, em menor escala, gêneros de pínus.

Estes florestamentos comerciais encontram-se desde as áreas mais altas da bacia hidrográfica, constituídas 
pelo Embasamento Pré-Cambriano, até a Planície Costeira. Segundo Cordeiro (2000), ocorrem pela demanda da mineração de argila nas cinco olarias existentes na bacia em questão, as quais se utilizam da madeira como combustível no processo de fabricação de cerâmicas.

Os campos tiveram, em geral, uma retração de sua área. Em 1988 somavam 6.882,7 hectares, e em 2002, 4.991,4 hectares. Esta retração ocorreu principalmente na porção NW/SE da área mapeada, onde houve o avanço das matas e área urbana, respectivamente. Em pontos específicos do espaço em estudo, notou-se a justaposição das áreas cobertas por gramíneas e mata, o que pode ser justificado por algumas atividades de criação de gado e outros animais, desenvolvidas pelos moradores locais.

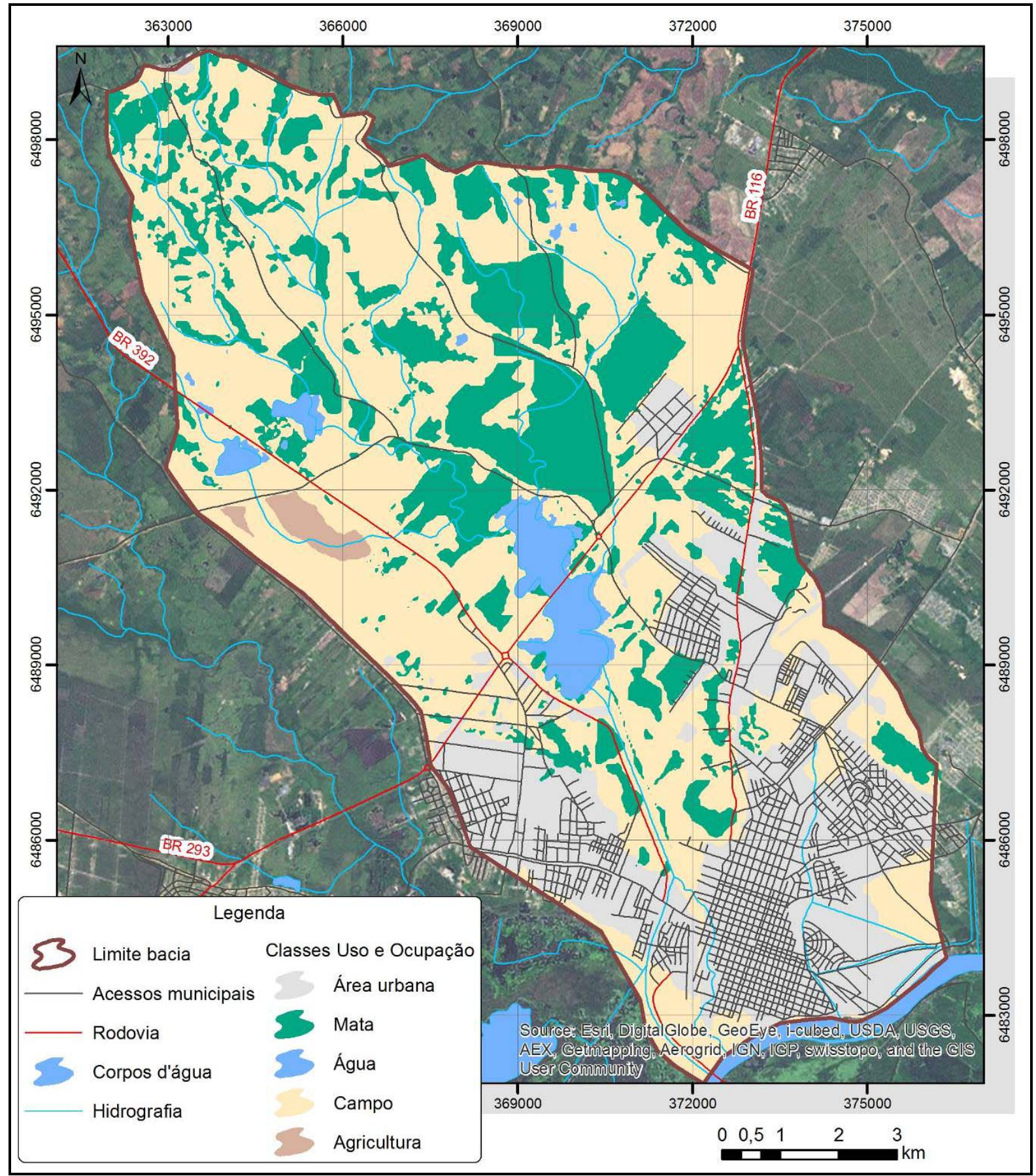

Figura 3: Mapa de Uso e Ocupação do Solo - Ano 1988 
Antropoceno - Tecnógeno

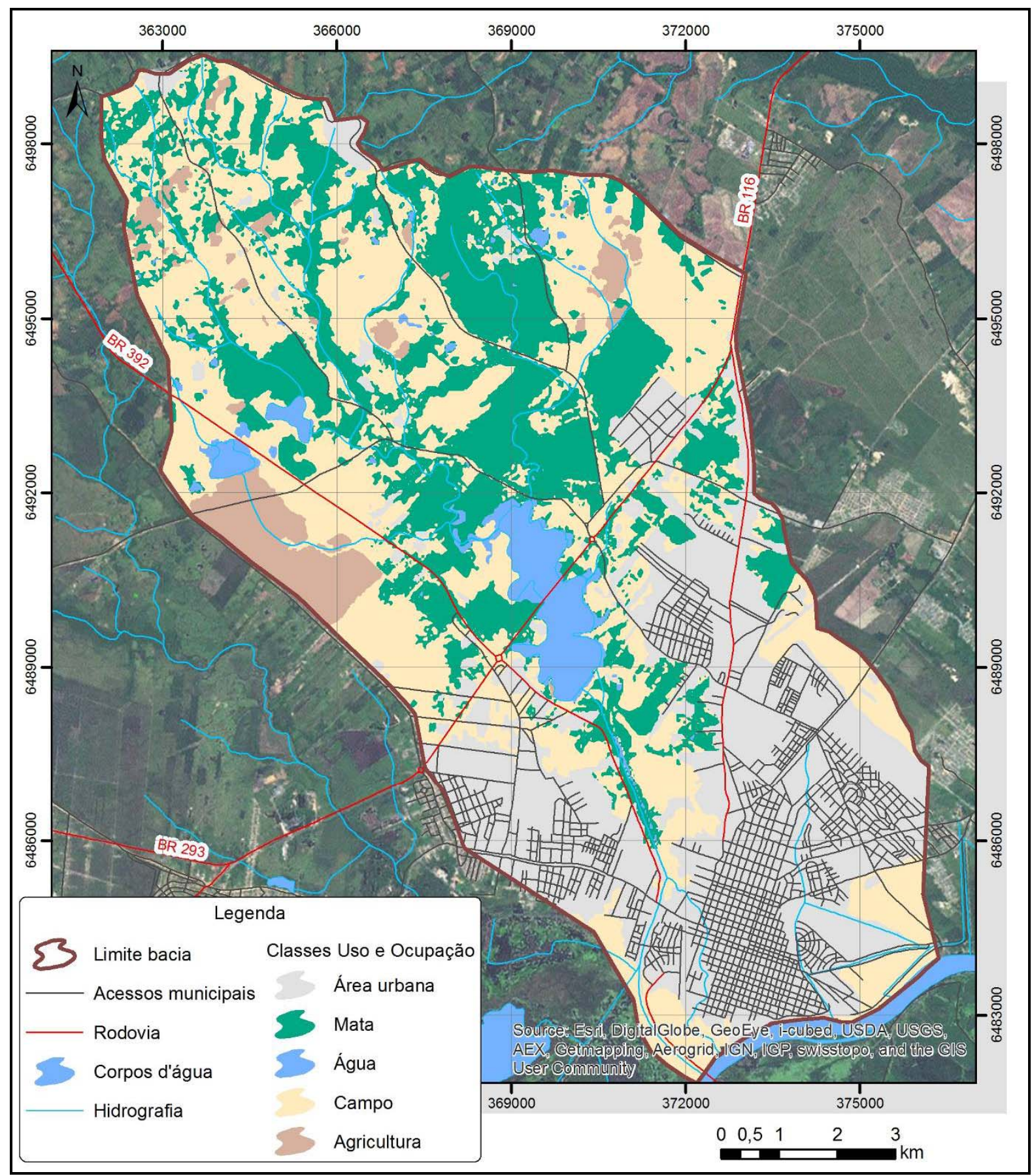

Figura 4: Mapa de Uso e Ocupação do Solo - Ano 2002

O sistema hídrico mapeado apresentou, em geral, aumento da área dos corpos de água somando, em 1988, 310,6 hectares e em 2002, 431,6 hectares. Esta variação da lâmina d'água pode estar associada às taxas de precipitação dos meses respectivos às imagens utilizadas (março, abril de 1988, outubro, novembro de 2002) que apresentaram, respectivamente, precipitação média mensal de 33,8 mm e 75,6 mm; 118,6 mm e 193,1 mm explicitando a área obtida nesta Classe.

\subsection{Os depósitos do Reservatório Santa Bárbara}

\section{Interpretação dos dados}

A técnica de utilização do testemunhador à percussão na coleta do material apresentou-se satisfatória diante das características da superfície de fundo. Quanto à profundidade de penetração dos tubos, houve variação entre os testemunhos, onde T1, T2, T3, T4, T5 apresentaram as diferentes e respectivas espessuras, 0,$40 ; 0,35 ; 0,71 ; 0,32 ; 0,72 \mathrm{~m}$. É provável que esta variação tenha ocorrido devido às pontuais diferenças litológicas do fundo, as quais não permitiram maior penetração.

Após a abertura dos testemunhos verificou-se que o material, em sua maioria, apresentou estruturas gradativas, horizontal ao plano basal, alternância gradual, de modo não uniforme, tanto de cores quanto de texturas e artefatos. Estas alternâncias em cada um dos testemunhos, possivelmente, encontram-se 
associadas, entre tantos outros fatores, a variações na velocidade da corrente dos arroios que desembocam no manancial, à morfologia de fundo do Reservatório, na constituição físico-química e concentração de matéria orgânica dos sedimentos, e às características dos processos que levaram ao transporte e deposição destes materiais.

Considerando a coloração dos grãos, foram encontradas tonalidades que gradam de um cinza a uma cor castanha, e os testemunhos T1 e T3 apresentaram mosqueamento indicando oxidação de grãos. As cores escuras/cinzentas encontradas podem estar relacionadas aos teores de matéria orgânica, presença de minerais oxidados e retrações da lâmina d'água, que possibilitou a oxidação de elementos férricos dos sedimentos.

No que tange aos aspectos texturais, os testemunhos diferenciaram-se entre si. Observou-se que nos estratos de cada um dos cinco, está o registro de uma alternância de fases de calmaria de decantação do material fino e períodos de maior capacitação dos cursos d'água para transportar o material grosseiro. Este registro delimita, ao mesmo tempo, fases de maior e/ou menor antropização, caracterizadas sob texturas que gradam de lama, lama com areia, areia com lama e areia, pela presença de artefatos humanos e concentração de material orgânico.

A figura 5 ilustra a representação esquemática dos testemunhos descritos com detalhe para as fases reconhecidas, texturas e constituição.

A ilustração da figura 5 revela que no T2 a presença tecnogênica ocorre nos dois primeiros fragmentos do testemunho, e no T4, em todo o estrato, da base ao topo. Contudo, nos T1 e T5 esta característica varia; no primeiro ocorre em torno dos $0,30 \mathrm{~cm}$ e, no segundo, nos $0,20 \mathrm{~cm}$ iniciais.

No T3, coletado na desembocadura do principal contribuinte do manancial, o arroio Santa Bárbara, a

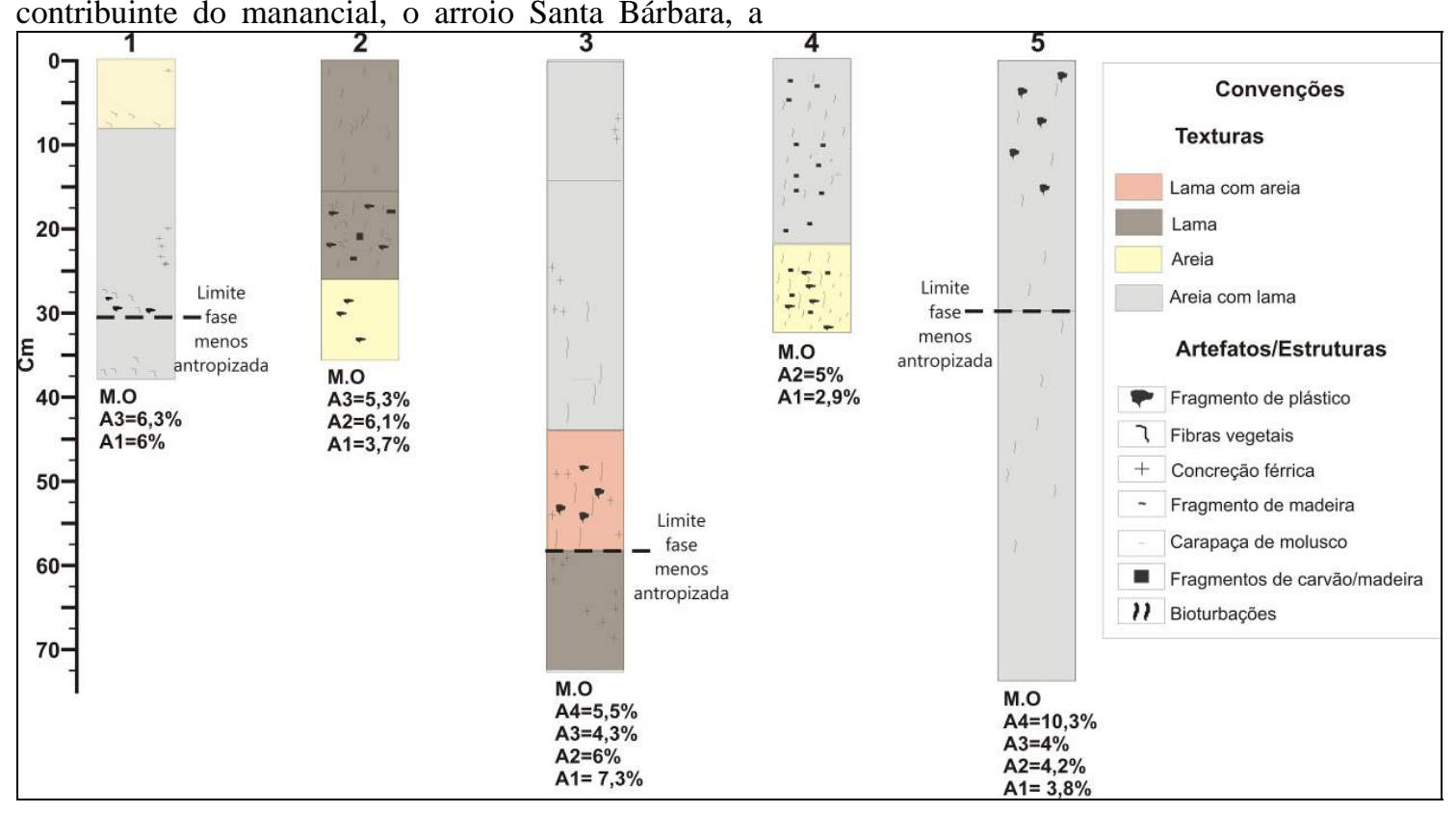

Figura 5: Representação esquemática dos testemunhos - Textura e constituição

Entre os cinco testemunhos, o T3 registrou características lineares de sedimentação. No entorno interface entre uma fase próxima da natural e outra representativa da tecnogênese foi nitidamente percebida próximo aos $0,60 \mathrm{~cm}$ da espessura do depósito. A partir deste testemunho traçou-se uma 'linha' que limitou a fase de menor/maior antropização.

Assim, o T3 como um divisor central, representou o ponto de partida para a interpretação das características de todos os outros, pois é o que mais se caracterizou com um comportamento linear de sedimentação, seja pela espessura ou composição. Apresentou no seu estrato basal textura lamosa, com concreções férricas, percentual 7,3\% de M.O., presença de bioturbações e, ausência de artefatos tecnogênicos. A partir de 0,60 cm de espessura deste pacote surgem artefatos manufaturados pelo homem moderno, como plásticos, demonstrando a ruptura, do ponto de vista da constituição, entre diferentes fases de sedimentação (natural/antropizada). Estas características, em conjunto com a presença de lama na base, são indicativas de um período de águas mais calmas ou de um entorno mais preservado, sem episódios de precipitações intensas, o que possibilitou a deposição de grãos menores, característicos de depósito de fundo de lago, sob uma situação natural. Os episódios posteriores, onde as características texturais gradam em direção ao topo para lama com areia, seguidos de areia com lama, mostram a intensificação da erosão e um maior transporte de material grosseiro, o que favoreceu o rápido soterramento desta lama e, ao mesmo tempo, constituíram obstáculos às novas deposições, levando aos possíveis desvios nos fluxos de água de fundo e continuidade destas deposições mais a jusante. Esta provável interpretação poderá ser corroborada em trabalhos futuros, através de testemunhagem em outros pontos das desembocaduras dos arroios. deste, verificou-se também significativa presença de mata (nativa, ciliar, reflorestamento). Esta classe 
(mata) ainda apresentou sensível aumento de área, conforme pode ser visualizado nos mapas de uso e ocupação do solo dos anos de 1988 e 2002.

A análise textural do T1, testemunho representativo de umas das extremidades das desembocaduras fluviais em análise, possibilitou caracterizá-lo com uma textura areno-lamosa em sua base e, no topo, arenosa com a presença de areia grossa mostrando que a tecnogênese naquele setor do reservatório se intensificou e propiciou a deposição dos sedimentos de maior granulometria. A ruptura entre 'natural' e antrópico ocorreu pela presença de artefatos no $\mathrm{T} 1$, em aproximadamente $0,32 \mathrm{~m}$ da espessura e aumento na concentração de M.O. de 6\% a 6,3\%.

A intensificação dos processos de transporte de materiais grosseiros, revelados pela característica textural do testemunho, possivelmente está associada às dinâmicas de escoamento superficial, intrinsecamente ligadas à expansão de ambientes construídos nas proximidades deste ponto de coleta. O reconhecimento destes ambientes nas proximidades deste ponto de amostragem, através do mapeamento, onde é visível a evolução da área urbana relativa a um período de 14 anos, e saídas de campo realizadas, revelou pontos com exposição de materiais superficiais originados pela substituição da cobertura vegetal em áreas construídas. Estes materiais, ao sofrer remobilização pelo escoamento superficial, possivelmente depositam-se no manancial, o que explicita a heterogênea composição textural encontrada.

Em outra extremidade da representação esquemática das fases identificadas, o T5 apresentou homogeneidade textural em todo o estrato, caracterizando-se como areia com lama. A superfície de ruptura das fases foi encontrada a aproximadamente 0,32m, onde, a partir daí, têm-se evidências tecnogênicas pelo aumento da concentração de M.O. de 3,8 a 10,3\% e presença de plásticos. Uma concentração alta de material orgânico, possivelmente justifica-se pela deposição da matéria fecal e águas servidas trazida pelo arroio contribuinte que drena área urbanizada. Estas concentrações de M.O. possivelmente também estão associadas à presença da pecuária de pequena escala exercida pela população que vive nas proximidades.

Constituição e comportamento textural diferenciado e heterogêneo ocorreram nos testemunhos T2 e T4, ao apresentarem em todo o estrato características de antropização. O T2 caracterizou-se por uma textura arenosa na base, com percentuais de M.O. em torno de $3,7 \%$, ao passo que, no topo, textura lamosa com 5,3\% de M.O. A espessura do pacote de lama presente neste testemunho indica um período contínuo de despejos de esgotos, provenientes das habitações a montante, diretamente nos cursos d'água e, através destes, no reservatório. O mapeamento de uso e ocupação do solo demonstrou aumento da ocupação urbana no entorno deste afluente, cujo testemunho foi coletado na desembocadura.

O T4 coletado no Setor do Arroio do Meio apresentou caráter tecnogênico desde a base ao topo, com texturas areia e areia com lama, respectivamente. Este caráter também se encontra associado ao aumento da concentração de material orgânico, que variou de 2,9 a 5\% (base-topo).

No entanto, foi através da análise realizada com uma lupa binocular que se encontraram evidências mais significativas da influência antrópica neste testemunho. A investigação com lupa apontou a força tecnogênica como de grande atuação, uma vez que em todas as amostras foi possível encontrar resquícios de artefatos humanos, tais como plástico e carvão - este último justificado pelo uso do reservatório para atividades de lazer pela população, que frequenta principalmente este ponto, pois apresenta facilidade de acesso. Em meio a estes materiais foi possível encontrar restos de vegetais e carapaças de moluscos, possivelmente abundantes pela proximidade de áreas com cobertura vegetal (mata, campo).

Um aspecto importante de se abordar, no que diz respeito à variação na concentração de M.O., é a possibilidade de os valores obtidos estarem associados às variações na vazão, no volume do reservatório e nas retrações da lâmina de água. Estas variáveis físicas, por sua vez, possuem estreita relação com os índices pluviométricos. Em períodos de baixa precipitação, quando as águas do reservatório têm seu nível rebaixado, acentua-se a acumulação do material em suspensão, inclusive de matéria orgânica. Entretanto, em períodos de condições de águas mais altas, com maior vazão e volume, são favorecidos a mobilização e o transporte deste material, provocando uma distribuição heterogênea de matéria orgânica na camada de material depositado e até mesmo sua redistribuição como deposição lateral em bancos próximos às margens e desembocaduras de arroios.

Assim, a concentração da matéria orgânica identificada inclui fontes naturais, como detritos orgânicos, vegetação marginal, organismos da coluna d'água e de fundo, restos da vegetação soterrada, quando do enchimento do reservatório, criação de animais, além de fontes antropogênicas, ou tecnogênicas, como efluentes domésticos e industriais.

As concentrações dos metais presentes nos depósitos apresentaram variações significativas principalmente para os metais chumbo $(\mathrm{Pb})$ e zinco $(\mathrm{Zn})$. Já o cromo $(\mathrm{Cr})$ e o cobre $(\mathrm{Cu})$ apresentaram tendência linear de concentração embora nas amostras T1A2 e T4A1, o Cu apresente valores mais elevados (figura 6). 


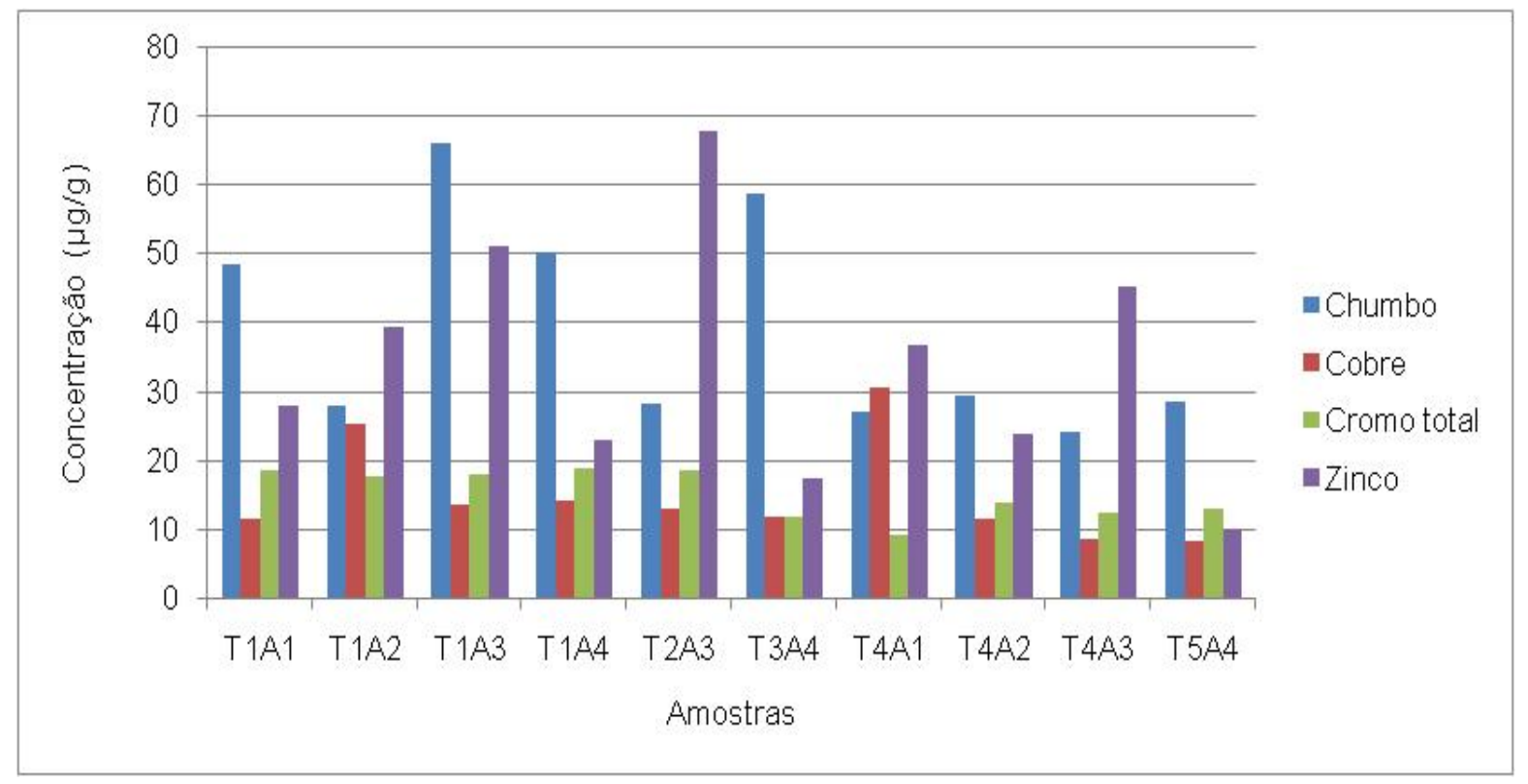

Figura 6: Concentração dos metais

Ao comparar os testemunhos 1 (T1) e 4 (T4), que tiveram todas as amostras da base ao topo analisadas, observam-se concentrações diferentes para cada metal. No $\mathrm{T} 1 \mathrm{o} \mathrm{Pb}$ apresenta a máxima concentração na amostra T1A3, próxima ao topo. Apresenta menor teor na base (T1A1) quando comparada ao topo (T1A4). O elemento $\mathrm{Cu}$ apresentou menor concentração na amostra da base (T1A1) que na de topo (T1A4).

Para o $\mathrm{Cr}$ verificou-se uma tendência uniforme nos valores, não sendo significativa a variação base-topo. $\mathrm{O}$ $\mathrm{Zn}$, juntamente com o $\mathrm{Pb}$, apresentou as maiores concentrações; contudo, o valor da amostra de topo (T1A4) é menor que na base (T1A1).

No $\mathrm{T} 4$ o $\mathrm{Pb}$ apresentou uma tendência mais uniforme e valores menores que no T1. A concentração mais elevada encontra-se na amostra T4A2, embora o valor da amostra da base do testemunho seja maior que na do topo. De modo semelhante, os elementos $\mathrm{Cu}, \mathrm{Cr}$ e $\mathrm{Zn}$ apresentaram maior concentração na amostra T4A1 (base) que na T4A3 (topo).

Quanto às amostras de topo, no T2 (T2A3) a concentração mais alta foi de $\mathrm{Zn}$, seguida de $\mathrm{Pb}$, $\mathrm{Cr}$ e $\mathrm{Cu}$, respectivamente. Porém, nos T3 (T3A4) e T5 (T5A4), verificaram-se concentrações mais altas, em ordem semelhante, de $\mathrm{Pb}, \mathrm{Zn}, \mathrm{Cr}$ e $\mathrm{Cu}$, respectivamente.

Ao serem comparadas as concentrações obtidas nas amostras de topo de cada um dos cinco testemunhos coletados verificou-se, portanto, que nos testemunhos T1, T3 e T5 os maiores valores correspondem ao elemento chumbo, e no T2 e no T4, ao metal zinco.

Quanto ao enriquecimento dos metais nos sedimentos, foram encontrados, para alguns elementos, valores de FC maiores que 1 , o que indica contaminação em relação ao background de Oliveira (2001). Todas as amostras de topo apresentaram certo enriquecimento de $\mathrm{Pb}$ (exceto no $\mathrm{T} 4$ ) e $\mathrm{Cu}$. Enriquecimento de Zn ocorre na amostra de topo do T2 e na A3 do T1, exatamente nas quais se verificou, através do gráfico anterior, maior concentração.

Os valores de Fator de Contaminação (FC) obtidos com o background de Oliveira (2001) demonstraramse, de modo geral, semelhantes às concentrações obtidas onde verificou-se maior concentração total de $\mathrm{Pb}, \mathrm{Zn}$ e $\mathrm{Cu}$, elementos que se destacam junto a este índice.

Quanto aos valores de FC obtidos com a utilização das médias globais (Turekian \& Wedepohl 1961, U.S.EPA apud Rodrigues 1997) como background, demonstraram enriquecimento apenas de $\mathrm{Pb}$ em todas as amostras dos testemunhos. Este resultado diferenciase do FC obtido anteriormente com os dados geoquímicos do Embasamento Pré-Cambriano. É possível, assim, dar preferência e enfatizar a importância da utilização de dados mais próximos da realidade estudada para que os resultados obtidos não sejam subestimados, embora os dados de Oliveira (2001) sejam geologicamente próximos.

A estimativa do Índice de Geoacumulação para os sedimentos coletados nos depósitos do Reservatório Santa Bárbara, para todos os níveis de base, apresentou o mesmo comportamento, ainda que com pequenas variações numéricas.

Ao se compararem os valores dos índices obtidos com os backgrounds utilizados, verificou-se que os metais $\mathrm{Pb}, \mathrm{Cu}, \mathrm{Cr}$ e $\mathrm{Zn}$ apresentam acumulação nos sedimentos entre 0 (zero) e 1 (um). Isto significa associação com a Classe Igeo 1, ou seja, pouco a moderadamente poluídos. Apenas a amostra de base do T4 diferenciou-se, associando-se à Classe 2, moderadamente poluído, quando comparado ao background de Oliveira (2001).

Quanto à acumulação antrópica, os dados de Fonseca et al. (1996) apud Torres et al. (2005) podem ser indicados como referência para diferentes atividades relacionadas a processos de acumulação antrópica. 
Segundo estes autores, as principais fontes antropogênicas de $\mathrm{Pb}, \mathrm{Cu}$, $\mathrm{Cr}$ e $\mathrm{Zn}$ incluem atividades como, por exemplo, fabricação ou reciclagem de baterias automobilísticas, soldagens, indústrias de tintas, oficinas mecânicas, artigos de microeletrônica, deposição atmosférica através da queima de combustíveis fósseis, uso de pesticidas, fertilizantes e adubos na agricultura e águas de irrigação, uso de agrotóxicos e lançamentos de efluentes domésticos.

As concentrações de $\mathrm{Pb}$ e $\mathrm{Zn}$ nos sedimentos do Reservatório Santa Bárbara, que se destacaram frente às demais, possivelmente estão associadas à contribuição antropogênica, pois conforme verificado em campo, os testemunhos apresentaram, em geral, sob sua retaguarda, além do Distrito Industrial, bairro urbano, florestamento e agricultura. Estas atividades representam potencial fonte de metais e corroboram a antropização verificada, anteriormente, na coluna de sedimentos dos testemunhos.

No sítio industrial, encontram-se ramos de metalurgia, comércio de peças usadas e de baterias automobilísticas, beneficiadora de cereais, restaurantes, postos de combustíveis, entre outros, e encontraram-se evidências de lançamento de cargas orgânicas e efluentes. Estes elementos podem estar se acumulando na fração fina do sedimento. Além deste fator de contribuição dos metais, existe a possibilidade de aporte pelas transposições de águas em períodos de estiagem do arroio Pelotas aos cursos de água alimentadores do reservatório, realizados pelo Serviço Autônomo de Saneamento de Pelotas (SANEP).

\section{Identificação e Classificação dos depósitos}

Derivados do assoreamento, os depósitos do Reservatório Santa Bárbara apresentaram características (constituição e forma de ocorrência) de antropização ambiental, constituindo o que, na atualidade, se denomina de "depósito tecnogênico".

Sua gênese possivelmente resulta de um processo em que a influência humana se deu somente nos processos (erosão, transporte, deposição), sendo o material constituinte predominantemente natural, podendo ser classificado, nesse sentido, como depósito tecnogênico induzido.

Pelo fato de apresentarem composição próxima à natural, soma-se ao termo induzido a categoria sedimentar, o que é indicativo de materiais que foram depositados por processos sedimentares induzidos pelas formas de apropriação do espaço, sendo análogos à sedimentação natural, com características e estruturas usuais dos sedimentos, porém de composição úrbica e gárbica.

Quanto à estrutura interna, os depósitos reconhecidos apresentaram um modo de organização sob a forma de estratos, paralelos ao plano basal, constituídos de sedimentos aluviais originados em ambiente urbano e também rural.

Estes elementos diferenciadores dos depósitos analisados, que por vezes mostraram-se semelhantes aos ditos naturais, permitem sua classificação aproximada: depósitos tecnogênicos induzidos sedimentares estratificados aluviformes de ambiente urbano e também rural.

Ainda que com as devidas limitações do background aqui utilizado, a determinação do Fator de Contaminação (FC) e do Índice de Geoacumulação (Igeo) complementa as características dos depósitos que, ao demonstrarem enriquecimento de chumbo, zinco e cobre, são, com base na classificação utilizada, considerados pouco a moderadamente poluídos. Este parâmetro, associado aos sedimentares, contribui para a identificação destes depósitos como tecnogênicos e de moderado risco à qualidade da água da represa.

\section{Considerações Finais}

Os procedimentos adotados, tanto no que diz respeito ao mapeamento do uso/ocupação do solo quanto à coleta e análise dos testemunhos geológicos, mostraram-se qualitativamente suficientes para atender os objetivos propostos.

Percebeu-se, em primeiro lugar, a relevância das abordagens do Quaternário, em sua fase mais recente, definida por muitos autores como Tecnógeno. O estudo interpretativo dos testemunhos da antropização ambiental, característicos deste tempo geológico, ao diagnosticar o presente, ajudou a esboçar o quadro da situação ambiental atual, além de constituir instrumento de discussão com vistas a atenuar um possível e futuro impacto negativo no espaço analisado.

Em um tempo atual (1988-2002), foram verificadas e mapeadas mudanças significativas no uso e ocupação do solo da bacia hidrográfica em questão. A espacialização e verificação de variações nas áreas das classes reconhecidas mostraram-se de relevância para o entendimento das possíveis causas no processo de constituição dos depósitos do Reservatório Santa Bárbara. Estas mudanças espaço-temporais do uso/ocupação do solo na bacia em questão podem, em conjunto, estar acelerando o assoreamento deste manancial.

O processo de assoreamento que vem ocorrendo no Reservatório Santa Bárbara, ao originar depósitos tecnogênicos, pode estar impactando ou vir a impactar o manancial, considerando que são basicamente constituídos de lixo (dejetos domésticos, como plástico e vidro) apresentando concentrações variadas de metal pesado e matéria orgânica nos sedimentos.

Neste sentido, a análise geoquímica dos sedimentos, trazidos pelos cursos fluviais, e que acabam depositando-se na desembocadura destes, junto ao reservatório, constituiu um modo adequado para diagnosticar a poluição geoquímica dos depósitos tecnogênicos. O diagnóstico deste aspecto mostrou-se qualitativamente preocupante, levando em consideração que o manancial abastece a população de Pelotas. As anomalias verificadas em pontos localizados, como T1 e T2, onde houve as maiores concentrações de $\mathrm{Pb}$ e $\mathrm{Zn}$, representam a adição direta de metais pesados ao sistema hídrico ou, 
alternativamente, manifestam o efeito das modificações físico-químicas impostas aos ambientes.

As modificações verificadas favorecem a acumulação anormal de metais pesados, já naturalmente presentes no ambiente. Esta situação ambiental pode se tornar um problema social de difícil administração. Uma vez que haja ressuspensão dos sedimentos de fundo à coluna d'água degrada-se a sua qualidade, podendo, assim, causar danos sanitários à população abastecida por este manancial.

As proposições de reconstituição da natureza, para minimizar os crescentes processos que alteram a dinâmica do Reservatório Santa Bárbara, principalmente os de assoreamento, responsáveis pela possível alteração na qualidade sanitária de suas águas, centram-se num controle mais efetivo da retirada de vegetação nas áreas de preservação, como áreas ribeirinhas, além da realocação das ocupações irregulares, implantação de sistemas de tratamento de esgotos e coleta de lixo eficiente, conscientização da população local visando diminuir o lançamento de lixo nos corpos d'água, e a remoção da mata ciliar, bem como disseminação de uma preocupação ambiental junto às atividades agrícolas e criação de animais.

Seria necessário também fornecer informações relevantes de cuidados ambientais e de como estes podem trazer benefícios e melhorias à qualidade de vida destas pessoas. A preocupação com a educação sanitária da população também é um ponto a ser destacado. Soluções práticas somente serão viáveis e darão bons resultados se acompanhadas de um esclarecimento à população, que será a maior beneficiada com os resultados obtidos.

Já se tem conhecimento das ações que o governo local, através do SANEP e de outras Secretarias, vem desenvolvendo para buscar a manutenção desse manancial, com fins de abastecimento e preservação ambiental. Tais ações centram-se em projetos de regularização fundiária, bem como na implantação de algumas redes coletoras de esgoto.

A obtenção de um diagnóstico da poluição na água e nos sedimentos, tanto no reservatório quanto em toda a bacia hidrográfica do arroio Santa Bárbara, é vislumbrada como proposta para estudos futuros.

Para tanto, sugere-se um estudo da hidrologia e morfometria desta bacia de drenagem, através da caracterização do regime de vazões e das taxas de sedimentação em diferentes períodos sazonais; um estudo da qualidade das águas superficiais com base em parâmetros físicos, químicos e biológicos e, ainda, um estudo geoquímico dos sedimentos de fundo dos arroios e do reservatório, através de comparações com um background específico da bacia hidrográfica.

Sem esgotar os aspectos referentes ao tema exposto, torna-se, por fim, evidente a necessidade de ampliação dos estudos da dinâmica ambiental que leva à gênese dos depósitos tecnogênicos associada à cartografia de uso do solo, às propostas de espacialização destas recentes formações superficiais e, ainda, à análise geoquímica multielementar, com vistas ao monitoramento e gestão ambientais.

\section{Agradecimentos}

Agradecemos à Coordenação de Aperfeiçoamento de Pessoal de Nível Superior (CAPES) pela Bolsa concedida para a realização desta pesquisa.

\section{Referências}

Chemekov Y.F. 1983.Technogenic deposits. In: Inqua Congress, II, Moscou, Abstracts... v.3, p.62.

Cordeiro L.H. 2000. Identificação e caracterização da bacia de captação do reservatório Santa Bárbara Pelotas - RS. Monografia de Graduação. Curso de Oceanologia. Departamento de Geociências. Fundação Universidade Federal do Rio Grande. 82p.

Esteves F. de A. 1988. Fundamentos de Limnologia. Rio de Janeiro: Interciência/FINEP. 575p.

Fanning D.J., Fanning M.C.B. 1989. Soil: morphology, genesis and classification. New York: John Wiley \& Sons. 395p.

Franzen M. 2001. Análise da contaminação por nutrientes, elementos maiores e elementos-traço nas águas e sedimentos do Arroio Sapucaia - RS. Dissertação de Mestrado. Pós-Graduação em Geociências. Instituto de Geociências. Universidade Federal do Rio Grande do Sul. 93p.

Hakanson L. 1980. An ecological risk index aquatic pollution control. A sedimentological approach. Water Res. 14: 975-1001.

Korb C.C. 2006. Identificação de Depósitos Tecnogênicos no Reservatório Santa Bárbara, Pelotas (RS). Dissertação de Mestrado. Pós-Graduação em Geografia. Instituto de Geociências. Universidade Federal do Rio Grande do Sul. 164p.

Müller G. 1979. Schwermetallen in den Sedimenten dês Rheins. Veranderrugen Seit, Umschau, 79:778-783.

Nolasco M.C. 1998. Depósitos Antrópicos/Tecnogênicos: Um conceito em discussão na Geologia. Monografia de Qualificação de Doutorado. Pós-Graduação em Geociências. Instituto de Geociências. Universidade Federal do Rio Grande do Sul. 63p.

Oliveira A.M.S. 1990. Depósitos Tecnogênicos associados à erosão atual. In: Congresso Brasileiro de Engenharia, 6, Salvador. Atas... Salvador, ABGE, 1:411-415.

Oliveira L.D. 2001. Geologia, Geoquímica e Geocronologia dos Granitóides Pós-Tectônicos à Zona de Cisalhamento Transcorrente de Porto Alegre, Extremo Nordeste do escudo SulRiograndense. Dissertação de Mestrado. Pós-Graduação em Geociências. Instituto de Geociências. Universidade Federal do Rio Grande do Sul. 100p.

Peloggia A.U.G. 1999. Sobre a classificação, enquadramento estratigráfico e cartografação dos solos e depósitos tecnogênicos. In: Prefeitura do Município de São Paulo/SEHAB/HABI/, Estudos de Geotécnica e Geologia Urbana (I). São Paulo, Manual Técnico 3 (GT-GEOTEC), p.35-50.

Pelotas, Prefeitura Municipal de. 1980. II Plano Diretor de Pelotas, Lei 2565/80. 73p.

Rodrigues M.L.K. 1997. Diagnóstico da poluição por elementostraço no sedimento da bacia hidrográfica do Rio Caí. Dissertação de Mestrado. Pós-Graduação em Ecologia. Instituto de Biociências. Universidade Federal do Rio Grande do Sul. 124p.

Shepard F.D. 1954. Nomenclatures based on sand-sil-clay rations. Journal of Sedimentary Petrology, v. 24, n.3. p.151-158.

Soares M.C.C. 2002. Avaliação Geoambiental da bacia Hidrográfica do Arroio do Salso, Porto Alegre, RS. Dissertação de Mestrado. Pós Graduação em Geociências, Departamento de Geologia, Universidade Federal do Rio Grande do Sul. 100p.

Ter-Stepanian G. 1988. Beginning of The Technogene. In: Bulletin of The International Association of Engineering Geology, France: IAEG, N 38, p.133-142.

Torres A.M., Bastos M.L.L., Boaventura G.R., Licht O.A.B., Kern D.C., Junior G.M., Frazão F.J.L., Costa M.L. da., Borba R.P., Figueiredo B.R. 2005. A Geoquímica dos Sedimentos e Solos. In: Souza C.R.G., Suguio K., Oliveira A.M.S., Oliveira P.E. de. (org.). Quaternário do Brasil. 1 ${ }^{\mathrm{a}}$ ed. Ribeirão Preto: Ed. Holos. p.298-320. 
Quaternary and Environmental Geosciences (2014) 05(1):41-54

\section{Antropoceno - Tecnógeno}

Turekian K.K., Wedepohl K.H. 1961. Distribution of the elements in some major units of the earth's crust. Bull. Geol. Soc. American. 72: $175-192$.

Wentworth C.R. 1922. A scale of grade and class terms of clastic sediments. Journal of Geology, v. 30. p. 377-392.

Wetzel R.G. 1975. Limnology. Rhkadelphia: W.B. Sauders. Company, 734p.

Recebido 17 de outubro de 2013 Aceito 06 de junho de 2014 